\title{
Pancreaticoduodenectomy with venous resection: an analysis of 30-day morbidity and mortality
}

\author{
Guilherme Hoverter CALLEJAS, Matheus Mathedi CONCON, Achiles Queiroz Monteiro de REZENDE, \\ Elinton Adami CHAIM, Francisco CALLEJAS-NETO and Everton CAZZO
}

\begin{abstract}
Background - Pancreaticoduodenectomy (PD) with the resection of venous structures adjacent to the pancreatic head, even in cases of extensive invasion, has been practiced in recent years, but its perioperative morbidity and mortality are not completely determined. Objective - To describe the perioperative outcomes of PD with venous resections performed at a tertiary university hospital. Methods - A retrospective study was conducted, classified as a historical cohort, enrolling 39 individuals which underwent PD with venous resection from 2000 through 2016 . Preoperative demographic, clinical and anthropometric variables were assessed and the main outcomes studied were 30-day morbidity and mortality. Results - The median age was 62.5 years (IQ 54-68); 55\% were male. The main etiology identified was ductal adenocarcinoma of the pancreas ( $82.1 \%$ ). In $51.3 \%$ of cases, the portal vein was resected; in $35.9 \%$, the superior mesenteric vein was resected and in the other $12.8 \%$, the splenomesenteric junction. Regarding the complications, $48.7 \%$ of the patients presented some type of morbidity in 30 days. None of the variables analyzed was associated with higher morbidity. Perioperative mortality was $15.4 \%$ (six patients). The group of individuals who died within 30 days presented significantly higher values for both ASA $(P=0.003)$ and ECOG $(P=0.001)$ scores. Conclusion - PD with venous resection for advanced pancreatic neoplasms is a feasible procedure, but associated with high rates of morbidity and mortality; higher ASA e ECOG scores were significantly associated with a higher 30-day mortality.

HEADINGS - Pancreatic neoplasms. Pancreaticoduodenectomy. Portal vein. Mesenteric veins. Mortality. Morbidity.
\end{abstract}

\section{INTRODUCTION}

More than $90 \%$ of the pancreatic tumors are carcinomas. Among these, moderately differentiated ductal adenocarcinoma predominates. It is characterized by its poor prognosis and low response to treatments such as chemotherapy and radiotherapy. More than $80 \%$ of tumors are detected after the invasion of adjacent structures, or even with distant metastases; even patients with resectable pancreatic carcinomas have an average 5-year survival below $20 \% \%^{(1-3)}$. Pancreatic cancer is responsible for more than 24,000 new cases of cancer and 20,000 deaths annually in the United States. In Brazil and other countries in the Southern hemisphere, it is less frequent than tumors of the esophagus, stomach and colon, accounting for $2 \%$ of all types of cancer. Genetic factors have been described and there is evidence that smoking raises the genetic risk, increasing up to 8-fold the risk in patients who have a family history of the disease. Smoking acts as an independent risk factor in patients with chronic pancreatitis, which in itself is already a risk factor, doubling the risk for these patients ${ }^{(4)}$. Both obesity and elevated caloric intake increase the risk for pancreatic carcinoma $^{(3,4)}$. Approximately $20 \%$ of pancreatic cancer patients have diabetes mellitus more than two years before diagnosis ${ }^{(4,5)}$.

The surgery of choice for lesions located in the pancreatic head is the pancreaticoduodenectomy (PD). Due to the anatomical peculiarity of this region, the pancreatic head rests on the splenomesenteric junction, where the portal vein is formed; in addition, the pancreatic neck is located exactly between the emergences of both the celiac trunk and the superior mesenteric artery. These factors promote a high risk of neoplastic invasion of these vascular structures ${ }^{(6-9)}$. Resection of vascular structures adjacent to the organ, even in cases of extensive invasion, has been practiced in recent years, but its perioperative outcomes are still poorly understood in our context, in addition to its impact on overall and disease-free survival ${ }^{(10-12)}$.

This study aims to describe the perioperative results of PD with venous resection performed at a public tertiary university hospital, in addition to identifying variables associated with perioperative morbidity and mortality.

\section{METHODS}

\section{Study design}

A retrospective study was conducted, classified as a historical cohort, enrolling individuals who underwent $\mathrm{PD}$ with venous resection and were then followed-up at the Pancreas and Biliary Surgery Outpatient Unit of a tertiary university hospital. The protocol of this study was submitted to the institutional Research Ethics Board and was approved under the reference number Unicamp-2.238.018/ CAAE: 72366817.9.0000.5404.

Individuals included underwent surgical procedures performed from 2000 through 2016. The data were obtained through medical records and outpatient worksheets. Participating individuals were identified through the electronic system of the surgery center of such service. The surgical outcomes observed during the first 30 days after resection surgery were considered. 


\section{Study population}

The casuistic included all patients aged at least 18 years old who underwent gastropancreaticoduodenectomy (GPD) or pylorussparing surgery (PD) with associated venous resection due to confirmed histopathological diagnosis of pancreatic cancer from 2000 to 2016. We excluded individuals who belonged to vulnerable groups (aged less than 18 years old, with mental disabilities, institutionalized), those with incomplete data in the medical records and those who underwent an associated resection of arterial vascular structures.

Sixty patients who met the criteria for inclusion in the initial data collection were identified. Of these, five were excluded because they presented a combined arterial resection, six because there was no report of venous resection in the surgical description, nine due to the unavailability and/or absence of complete data in medical records and one due to the histopathological diagnosis of chronic pancreatitis. Thus, 39 patients were included in the present study (FIGURE 1)

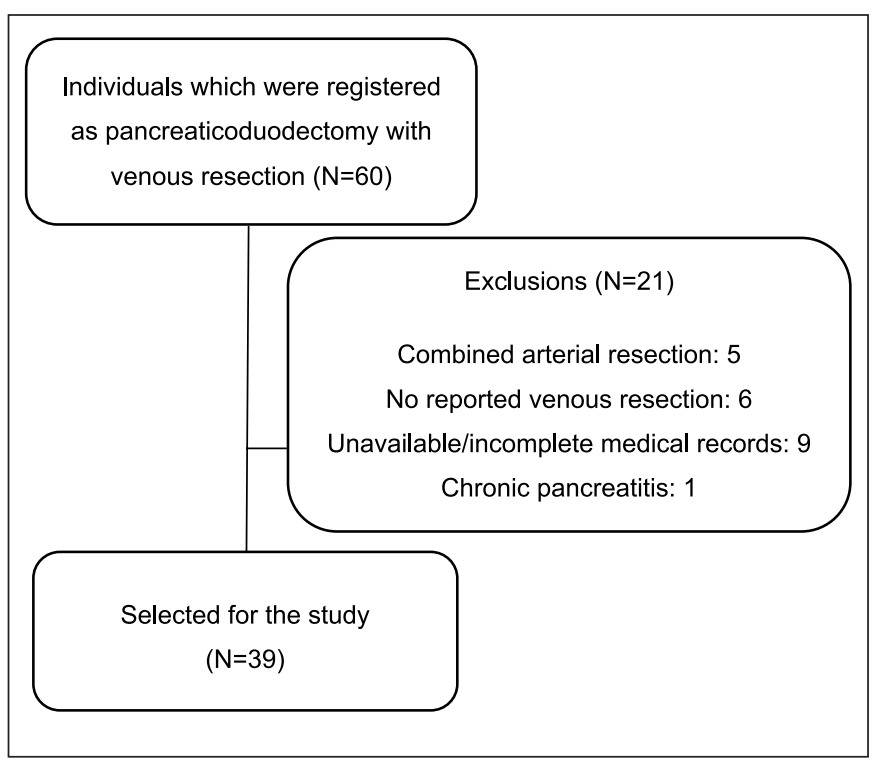

FIGURE 1. Flowchart of the study population.

\section{Analyzed variables}

The variables and concepts used in this study were: a) age: (years at the time of surgery); b) gender; c) ethnicity according to self-declaration; d) body mass index (BMI) $\left(\mathrm{kg} / \mathrm{m}^{2}\right)$; e) symptoms; f) physical status according to the American Society of Anesthesiologists (ASA); g) performance status according to the Eastern Cooperative Oncology Group (ECOG); h) preoperative endoscopic retrograde cholangiopancreatography (ERCP); i) length of stay (days); j) estimated intraoperative bleeding $(\mathrm{mL}) ; \mathrm{k})$ type of reconstruction (single or double-loop); 1) operative time (minutes); m) 30-day morbidity; n) 30-day operative mortality.

\section{Surgical technique}

All procedures were performed by the same surgical team. The procedures were performed according to the standard technique, along with an extended lymphadenectomy (hepatic hilum, celiac trunk, splenic artery, superior mesenteric artery, infra and suprapyloric lymph nodes); reconstruction was carried out by means of single-loop (duodenojejunostomy, hepaticojejunostomy and pancreaticojejunostomy) or double loop (gastrojejunostomy or duodenojejunostomy, hepaticojejunostomy, pancreaticojejunostomy and entero-enteric anastomoses). Venous resection was usually performed after the Whipple maneuver; the reconstruction was performed according to the resected segment, and could be done through tangential suture, end-to-end anastomosis and/or use of an autologous graft of the safenous vein.

\section{Statistical analysis}

Descriptive analysis with presentation of frequency tables for categorical variables and position and dispersion measurements for numerical variables. The normality of the data was evaluated using the Shapiro-Wilk test. Given that the distribution was not Gaussian, the results were expressed in medians and interquartile ranges (IQ). For the comparison of proportions, the chi-square test or Fisher's exact test was used when necessary. MannWhitney test was used to compare continuous variables between two independent groups. For the comparison of continuous variables between three or more groups, the Kruskal-Wallis test was used. The significance level adopted for the statistical tests was $5 \%(P<0.05)$. The value of $P$ was adjusted for the univariate analysis according to the Bonferroni's correction (the adjusted value of $P$ for significance was below 0.005 ). For the execution of the analysis, it was used the SAS System for Windows (Statistic Analysis System), version 9.2; SAS Institute Inc., 2002-2008, Cary, NC, USA.

\section{RESULTS}

The characteristics of the studied population are detailed in TABLE 1.

TABLE 1. Characteristics of the study population.

\begin{tabular}{lc}
\hline Variable & \\
\hline $\mathrm{N}$ & 62.5 (IQ 54-68) \\
Age (years) & \\
Gender & $55 \%$ \\
Male & $45 \%$ \\
Female & \\
Self-declared ethnicity & $76.9 \%$ \\
White & $23.1 \%$ \\
$\quad$ Black/Brown & \\
Symptoms & $71.8 \%$ \\
Jaundice & $71.8 \%$ \\
Weight loss & $33.3 \%$ \\
Inappetence & $24(\mathrm{IQ}: 21.9-26.8)$ \\
BMI (kg/m $\left.{ }^{2}\right)$ & \\
Etiology & $32(82 \%)$ \\
Ductal adenocarcinoma & $2(5.1 \%)$ \\
Neuroendocrine tumor & $5(12.8 \%)$ \\
Other tumors & \\
\hline
\end{tabular}

$\mathrm{N}$ : number of individuals; BMI: body mass index. 
In regards to the surgical technique, $71.7 \%$ of the subjects underwent GPD, whereas in $28.3 \%$ it was adopted a pylorus-sparing technique. The majority of the individuals underwent a single-loop reconstruction $(53.8 \%)$. The median operative time was $335 \mathrm{~min}$ (IQ: $300-420 \mathrm{~min}$ ) and the estimated bleeding $1000 \mathrm{ml}$ (IQ 800-2000 $\mathrm{mL}$ ). In $51.3 \%$ of cases, the portal vein was resected, whereas in $35.9 \%$, the superior mesenteric vein was resected and in the other $12.8 \%$, the splenomesenteric junction. The median length of hospital stay was 12.5 days (QI: 9.75-15).

The adopted tactics for venous resection and reconstruction were: tangential resection with a simple suture $(76.9 \%)$, complete resection with end-to-end anastomosis $(18 \%)$, and complete resection with autologous venous graft (5.1\%).

In relation to perioperative complications, $48.7 \%$ of the patients had some type of morbidity in 30 days, with intracavitary abscesses (17.9\%), bleeding (12.8\%) and pancreatic fistulas $(12.8 \%)$ being more common. Other complications observed were ascites, digestive hemorrhage, and respiratory complications. (TABLE 2) None of the variables analyzed was associated with higher morbidity (TABLE 3 ).

TABLE 2. Perioperative complications.

\begin{tabular}{lc}
\hline Complication & $\mathbf{N}(\%)$ \\
\hline Intracavitary abscess & $7(17.9 \%)$ \\
Hemorrhage & $5(12.8 \%)$ \\
Pancreatic fistula & $5(12.8 \%)$ \\
Ascites & $2(5.1 \%)$ \\
Respiratory complications & $3(7.7 \%)$ \\
Others & $4(10.3 \%)$ \\
Overall morbidity & $19(48.7 \%)$ \\
\hline
\end{tabular}

Perioperative mortality was $15.4 \%$ (6 patients). The group of individuals who died within 30 days presented significantly higher values for both ASA $(P=0.003)$ and $\operatorname{ECOG}(P=0.001)$ scores. The other variables analyzed did not differ between groups according to mortality. TABLE 4 details these observations.

\section{DISCUSSION}

The first description of PD associated with a vascular resection was done more than 40 years ago, but only recently this has become a widely used approach for advanced tumors ${ }^{(13,14)}$. Historically, there was resistance to this approach due to the technical difficulty and the possibility that the survival gain could be negligible, given that the risk that the individuals presented systemic already undetected disease before the surgery was considerable. Recent studies have shown that the overall survival of patients who underwent PD with venous resection is comparable to those who underwent a standard resection, suggesting that venous involvement is more indicative of tumor location than of its biological behavior ${ }^{(15,16)}$. According to a systematic review conducted by Gurusamy et al. ${ }^{(17)}$, pancreatic resection can be considered for selected patients with locally advanced pancreatic cancer at referral centers, assuming a higher risk of morbidity and mortality associated with the procedure. The same study, however, points out that there is a great heterogeneity and most of the studies that support this conclusion are of poor quality. There are no ultimate conclusions according to the current literature in regard to the best venous reconstruction method. Liao et al. ${ }^{(18)}$ demonstrated that prosthetic grafts are safe and effective, but there was no advantage in comparison with autologous grafts in regards to perioperative outcomes.

The epidemiological profile of the individuals in the present study was comparable to that previously described in the literature,

TABLE 3. Univariate analysis of factors associated with 30-day morbidity.

\begin{tabular}{|c|c|c|c|}
\hline Variable & Occurrence of morbidity & Absence of morbidity & Value of $P$ \\
\hline $\mathrm{N}$ & 19 & 20 & $\mathrm{~N} / \mathrm{A}$ \\
\hline Age (years) & 60 (IQ: 54-68) & 59.5 (IQ: 48-67) & 0.9 \\
\hline Male & $57.1 \%$ & $50 \%$ & \multirow{2}{*}{0.7} \\
\hline Female & $42.9 \%$ & $50 \%$ & \\
\hline BMI $\left(\mathrm{kg} / \mathrm{m}^{2}\right)$ & 24 (IQ: 18-27) & 24.5 (IQ: 19-27) & 1 \\
\hline ECOG & 1 (IQ: 0-2) & 1 (IQ: 0-1) & 0.8 \\
\hline Operative time (minutes) & 360 (IQ: 300-540) & 360 (IQ: 300-480) & 0.9 \\
\hline Estimated bleeding (mL) & 1200 (IQ: 600-1600) & 1000 (IQ: 600-1400) & 0.3 \\
\hline Preoperative ERCP & $72.2 \%$ & $57.1 \%$ & 0.3 \\
\hline \multicolumn{4}{|l|}{ Resected vein } \\
\hline \multicolumn{4}{|l|}{ Type of reconstruction } \\
\hline Single-loop & $52.6 \%$ & $55 \%$ & \multirow{2}{*}{0.9} \\
\hline Double-loop & $47.4 \%$ & $45 \%$ & \\
\hline
\end{tabular}

N/A: not applicable; N: number of individuals; IQ: interquartile range; BMI: body mass index; ASA: American Society of Anesthesiologists physical status classification; ECOG: Eastern Cooperative Oncology Group performance status; ERCP: endoscopic retrograde colangiopancreatography; PV: portal vein; SMV: superior mesenteric vein; SMJ: splenomesenteric junction. Adjusted value of $\mathrm{P}$ for significance after Bonferroni's correction: $P<0.005$. 
TABLE 4. Univariate analysis of factors associated with 30-day mortality.

\begin{tabular}{|c|c|c|c|}
\hline Variable & Occurrence of mortality & Absence of mortality & Value of $P$ \\
\hline $\mathrm{N}$ & 6 & 33 & $\mathrm{~N} / \mathrm{A}$ \\
\hline Gender (male) & $71.4 \%$ & $51.5 \%$ & 0.9 \\
\hline ASA & 3 (IQ: 2-3) & 2 (IQ: 2) & 0.003 \\
\hline ECOG & 2 (IQ: 1-2) & 1 (IQ: 0-1) & 0.001 \\
\hline Operative time (minutes) & 420 (IQ: 335-435) & $330(300-420)$ & 0.1 \\
\hline Preoperative ERCP & $57.1 \%$ & $33.3 \%$ & 0.3 \\
\hline \multicolumn{4}{|l|}{ Resected vein } \\
\hline PV & $66.6 \%$ & $48.5 \%$ & \\
\hline SMV & $16.7 \%$ & $39.4 \%$ & \\
\hline SMJ & $16.7 \%$ & $12.1 \%$ & 0.9 \\
\hline \multicolumn{4}{|l|}{ Type of reconstruction } \\
\hline
\end{tabular}

N/A: not applicable; N: number of individuals; IQ: interquartile range; BMI: body mass index; ASA: American Society of Anesthesiologists physical status classification; ECOG: Eastern Cooperative Oncology Group performance status; ERCP: endoscopic retrograde colangiopancreatography; PV: portal vein; SMV: superior mesenteric vein; SMJ: splenomesenteric junction. Adjusted value of $P$ for significance after Bonferroni's correction: $P<0.005$.

with a predominance of males from the sixth decade of life $\mathrm{e}^{(1-3)}$. There was a predominance of self-declared Whites, and there is evidence in the literature of a higher prevalence of the disease in Blacks. Possible explanations for this discrepancy may relate to the predominantly mixed ethnicity in our country, as well as complex socioeconomic issues that may lead to a possible delayed access to healthcare services and postponing the diagnosis and referral for potentially curative treatment among these poorer populations ${ }^{(19,20)}$.

Although the arterial resection presents caveats due to the high perioperative morbimortality, tumors with suspected venous invasion can be resected with results close to those observed in the standard procedure. Nigri et al. ${ }^{(21)}$, analyzing in a multicenter study the evolution of venous resections in pancreatectomies in Italy, observed mortality ranging from $5.3 \%$ to $9.2 \%$. In a 2012 meta-analysis involving 19 studies conducted by Zhou et al. ${ }^{(22)}$, it was observed that, despite greater bleeding and operative time in patients who underwent surgery with venous resection, morbidity, perioperative mortality and survival at 1,3 and 5 years were similar in relation to the group who underwent standard surgery.

The present study demonstrated similar results regarding surgical time, blood loss and perioperative morbidity to those observed in some international studies. Beane et al., in a study involving 194 patients who underwent PD with venous resection included in a database of the American College of Surgeons, reported a morbidity of $46.7 \%$, and $11.6 \%$ of the patients had pancreatic fistula $^{(23)}$. In a study by Hamidian-Jahromi et al. ${ }^{(24)}$, involving 17 patients undergoing pancreatectomy with venous resection, the median estimated blood loss was $997 \mathrm{~mL}$ and the surgical time was 400 minutes.

Although there is not a universally accepted goal for perioperative mortality, the value observed in our study (15.4\%) was high. In the above-mentioned meta-analysis, perioperative mortality was $3.3 \%$ in patients which underwent venous resection ${ }^{(22)}$. On the other hand, the mortality of the present study result was comparable to the indices found in Brazilian studies referring to the standard procedure. In a recent retrospective study conducted at our institution with patients undergoing PD (with or without vascular resection) between 2012 and 2017, the overall mortality observed was $10.3 \%{ }^{(13)}$. Analyzing the standard surgery without vascular resection, Rocha et al. ${ }^{(25)}$, in a sample of 41 patients, observed morbidity of $58 \%$ and surgical mortality of $22 \%$. Wanderlay et al. ${ }^{(26)}$, analyzing 21 patients, verified a morbidity of $21.7 \%$ and mortality of $17.3 \%$. Torres et al. ${ }^{(27)}$, in 39 patients who underwent a standard operation, observed a 30 -day mortality of $10.2 \%$.

Preoperative biliary drainage by means of ERCP did not influence perioperative outcomes in the current study. However, this is a controversial topic, since this approach may lead to more infectious complications after $\mathrm{PD}^{(28)}$, although as it has been pointed by $\mathrm{Ngu}$ et al. ${ }^{(29)}$, the avoidance of preoperative biliary drainage will prove logistically difficult for most hepato-pancreato-biliary units. A metaanalysis conducted by Wang et al. ${ }^{(30)}$ concluded that the current evidence neither supports nor refutes pre-operative biliary drainage for patients with obstructive jaundice needing surgery; however, this review also highlighted the heterogeneity and poor quality of most analyzed studies. Our service adopts this approach based on the high levels of bilirubinemia of our patients at admittance allied with the impossibility to indicate a definitive surgery in an emergency setting.

Certain factors seem to have been determinant for the mortality observed in the current study. It was observed, mainly, that a more precarious clinical status assessed by both ASA and ECOG scores was associated with a higher mortality, as previously pointed out by Chou et al. ${ }^{(31)}$ The socioeconomic profile of patients in our country is strongly reflected in terms of nutritional status and access to health services. Thus, these are patients whose diagnosis is very late and who, in most cases, are admitted with clinical and nutritional conditions already significantly deteriorated in the referral service ${ }^{(32,33)}$. There is strong evidence that the results of general and oncologic surgical treatments for pancreatic cancer are significantly worse in populations with more precarious socioeconomic status due to issues such as a difficulty to access referral services and their generally deteriorated health status ${ }^{(34-36)}$. Even though the surgery corresponds to the only curative therapy for this disease, it is possible to assume that alternative approaches to resection as the first therapeutic modality, such as neoadjuvant 
therapy with chemo and radiotherapy, or even treatments based on palliation of complications arising from these neoplasms, such as biliary drainage or bypass through gastroenterostomy, could be more appropriate in individuals with more advanced age, comorbidities or precarious nutritional status. Still, we must consider that the study encompasses a long period, with results that may vary over time due to the progression of the learning curve and skills of the surgical team. Hence, the selection of suitable patients to undergo these surgical procedures seems to be the key point to better outcomes, and the use of general physical and clinical status are useful to this decision-making process.

The current study presents some limitations that must be taken into consideration. Its retrospective design may be associated with a lower quality of the data collected, as well as the potential loss of participants due to the incomplete medical reports. The option for a single-center study does not allow the findings to be immediately reproducible in other services. In addition, the small sample precludes ultimate conclusions. A comparative study involving individuals undergoing this procedure, standard surgery or palliative therapies could also bring relevant information.

\section{CONCLUSION}

PD with venous resection for advanced pancreatic neoplasms is a feasible procedure, but associated with high rates of morbidity and mortality. Higher ASA e ECOG scores were significantly associated with a higher 30-day mortality.

\section{Statement of informed consent}

Informed consent was obtained from all individual participants included in the study.

\section{Statement of human and animal rights}

All procedures performed in studies involving human participants were in accordance with the ethical standards of the institutional and/or national research committee and with the 1964 Helsinki declaration and its later amendments or comparable ethical standards.

\section{Authors' contribution}

Callejas GH collected the data and wrote the first draft of the study. Concon MM and Rezende AQM provided clinical assistance for the individuals enrolled in the study. Chaim EA contributed relevant intellectual inserts. Callejas-Neto F performed the surgical procedures. Cazzo E designed the study and wrote substantial portions of the study.

\section{Orcid}

Guilherme Hoverter Callejas. Orcid: 0000-0002-7952-7379.

Matheus Mathedi Concon. Orcid: 0000-0001-9445-5839.

Achiles Queiroz Monteiro de Rezende. Orcid: 0000-00029696-7616.

Elinton Adami Chaim. Orcid: 0000-0001-9370-9518.

Francisco Callejas Neto. Orcid: 0000-0001-6023-187X.

Everton Cazzo. Orcid: 0000-0002-5804-1580.

Callejas GH, Concon MM, Rezende AQM, Chaim EA, Callejas-Neto F, Cazzo E. Duodenopancreatectomia com ressecção venosa: análise de morbidade e mortalidade em 30 dias. Arq Gastroenterol. 2019;56(3):246-51.

RESUMO - Contexto - A duodenopancreatectomia (DP) com ressecção de estruturas venosas adjacentes à cabeça do pâncreas, mesmo em casos de invasão extensa, tem sido praticada nos últimos anos, mas sua morbidade e mortalidade perioperatórias não são completamente determinadas. Objetivo - Descrever os resultados perioperatórios de DP com ressecções venosas realizadas em um hospital terciário universitário. Métodos - Foi realizado estudo retrospectivo, classificado como coorte histórica, envolvendo 39 indivíduos submetidos à DP com ressecção venosa entre 2000 e 2016. Foram estudadas variáveis demográficas, clínicas e antropométricas pré-operatórias e os desfechos principais foram a morbidade e mortalidade em 30 dias. Resultados - A mediana de idade foi 62,5 anos (IQ 54-68), sendo 55\% dos indivíduos do sexo masculino. A principal etiologia identificada foi o adenocarcinoma ductal de pâncreas (82,1\%). Em 51,3\% dos casos, a veia porta foi submetida à ressecção; em 35,9\%, a veia mesentérica superior foi ressecada e nos outros 12,8\%, a junção esplenomesentérica. Em relação às complicações, $48,7 \%$ dos pacientes apresentaram algum tipo de morbidade em 30 dias. Nenhuma das variáveis analisadas associou-se à maior morbidade. A mortalidade perioperatória foi 15,4\% (seis pacientes). O grupo de indivíduos que cursou com mortalidade em 30 dias apresentou escores significativamente mais altos de ASA $(P=0,003)$ e ECOG $(P=0,001)$. Conclusão - A DP com ressecção venosa para neoplasias avançadas do pâncreas é um procedimento factível, porém que se acompanha de altos índices de morbidade e mortalidade; escores de ASA e ECOG altos são fatores significativamente associados à maior mortalidade.

DESCRITORES - Neoplasias pancreáticas. Pancreaticoduodenectomia. Veia porta. Veias mesentéricas. Mortalidade. Morbidade.

\section{REFERENCES}

1. Ma J, Siegel R, Jemal A. Pancreatic cancer death rates by race among US men and women, 1970-2009. J Natl Cancer Inst. 2013;105:1694.

2. Oliveira MM, Malta DC, Guauche H, Moura L, Azevedo e Silva G. [Estimated number of people diagnosed with cancer in Brazil: data from the National Health Survey, 2013] [Article in Portuguese]. Rev Bras Epidemiol. 2015; 18(Suppl 2):146-57.

3. Petersen GM, de Andrade M, Goggins M, Hruban RH, Bondy M, Korczak JF, et al. Pancreatic cancer genetic epidemiology consortium. Cancer Epidemiol Biomarkers Prev. 2006;15:704-10.

4. Govindarajan A, Tan JC, Baxter NN, Coburn NG, Law CH. Variations in surgical treatment and outcomes of patients with pancreatic cancer: a population-based study. Ann Surg Oncol. 2008;15:175-85.
5. Rahn S, Zimmermann V, Viol F, Knaack H, Stemmer K, Peters L, et al. Diabetes as risk factor for pancreatic cancer: Hyperglycemia promotes epithelial-mesenchymal-transition and stem cell properties in pancreatic ductal epithelial cells Cancer Lett. 2018;415:129-50.

6. Yeo CJ, Cameron JL, Sohn TA, Lillemoe KD, Pitt HA, Talamini MA, et al. Six hundred fifty consecutive pancreaticoduodenectomies in the 1990s: pathology, complications, and outcomes. Ann Surg. 1997;226:248-57.

7. Suzuki Y, Fujino Y, Ajiki T, Ueda T, Sakai T, Tanioka Y, Kuroda Y. No mortality among 100 consecutive pancreaticoduodenectomies in a middle-volume center. World J Surg. 2005;29:1409-14 
8. Cameron JL, Pitt HA, Yeo CJ, Lillemoe KD, Kaufman HS, Coleman J. One hundred and forty-five consecutive pancreaticoduodenectomies without mortality. Ann Surg. 1993;217:430-5; discussion 435-8.

9. Aranha GV, Hodul PJ, Creech S, Jacobs W. Zero mortality after 152 consecutive pancreaticoduodenectomies with pancreaticogastrostomy. J Am Coll Surg. 2003;197:223-31; discussion 231-2

10. Abou-Khalil J, Rocha FG. Surgical strategies and novel therapies for locally advanced pancreatic cancer. J Surg Oncol. 2017;116:16-24.

11. Hoshimoto S, Hishinuma S, Shirakawa H, Tomikawa M, Ozawa I, Wakamatsu $\mathrm{S}$, et al. Reassessment of the clinical significance of portal-superior mesenteric vein invasion in borderline resectable pancreatic cancer. Eur J Surg Oncol. 2017;43:1068-75

12. Wang M, Zhang H, Zhu F, Peng F, Wang X, Shen M, Qin RY. Pancreaticoduodenectomy for borderline resectable pancreatic head cancer with a modified artery-first approach technique. Hepatobiliary Pancreat Dis Int. 2017;16:215-21.

13. Rezende AQM, Dutra JPS, Gestic MA, Utrini MP, Chaim EA, Callejas-Neto F, Cazzo E. Pancreaticoduodenectomy: impact of the technique on operative outcomes and surgical mortality. Arq Bras Cir Dig. 2019;32:e1412.

14. Moore GE, Sako Y, Thomas LB. Radical pancreaticoduodenectomy with resection and reanastomosis of the superior mesenteric vein. Surgery 1951; 30:550-3.

15. Cherukuru R, Govil S, Vij M, Rela M. Vein resection in patients with adenocarcinoma of the head of pancreas adherent to the portomesenteric venous axis is beneficial despite a high rate of $\mathrm{R} 1$ resection. Ann Hepatobiliary Pancreat Surg. 2018;22:261-8.

16. Flis V, Potrc S, Kobilica N, Ivanecz A. Pancreaticoduodenectomy for ductal adenocarcinoma of the pancreatic head with venous resection. Radiol Oncol. 2016;50:321-8.

17. Gurusamy KS, Kumar S, Davidson BR, Fusai G. Resection versus other treatments for locally advanced pancreatic cancer. Cochrane Database Syst Rev. 2014;(2):CD010244.

18. Liao K, Wang H, Chen Q, Wu Z, Zhang L. Prosthetic graft for superior mesenteric-portal vein reconstruction in pancreaticoduodenectomy: a retrospective, multicenter study. J Gastrointest Surg. 2014;18:1452-61.

19. Soldan M. Pancreatic cancer screening. Rev Col Bras Cir. 2017;44:109-111.

20. Apodaca-Rueda M, Chaim FHM, Garcia MDS, Saito HPA, Gestic MA, Utrini MP, et al. Solitary pancreatic metastasis from breast cancer: case report and review of literature. Sao Paulo Med J. 2017. doi: 10.1590/1516-3180.2017.0144260617.

21. Nigri G, Petrucciani N, Pinna AD, Ravaioli M, Jovine E, Minni F, et al. Evolution of pancreatectomy with en bloc venous resection for pancreatic cancer in Italy. Retrospective cohort study on 425 cases in 10 pancreatic referral units. Int J Surg. 2018;55:103-9.

22. Zhou Y, Zhang Z, Liu Y, Li B, Xu D. Pancreatectomy combined with superior mesenteric vein-portal vein resection for pancreatic cancer: a meta-analysis. World J Surg. 2012;36:884-91.
23. Beane JD, House MG, Pitt SC, Zarzaur B, Kilbane EM, Hall BL, et al. Pancreatoduodenectomy with venous or arterial resection: a NSQIP propensity score analysis. HPB (Oxford). 2017;19:254-63.

24. Hamidian-Jahromi A, Jafarimehr E, Dabbous HM, Chu Q, D’Agostino H, Shi $\mathrm{R}$, et al. Curative resection of pancreatic adenocarcinoma with major venous resection/repair is safe procedure but will not improve survival. JOP. 2014;15: 433-41.

25. Rocha LCG, Queiroz FL, Magalhães EA, Santos FAV, Caldeira DAM, Ribas MA. [Pancreaticoduodenectomy: results in 41 patients]. [Article in Portuguese]. Rev Col Bras de Cir. 2006;33:387-92.

26. Wanderlay GJP, Andrade RTM, Martins ACA, Santos Jr MA, Evangelista LFL, Sá VCT. [Duodenopancreatectomy: post-operative morbi-mortality]. [Article in Portuguese]. An Fac Med Univ Fed Pernamb. 2005;50:7-10.

27. Torres OJM, Barbosa ES, Barros NDC, Barros CA, Ferreira EDZ, Pereira HC. Pancreaticoduodenectomies: analysis of 39 patients. Rev Col Bras Cir. 2007; 34:21-4.

28. De Pastena M, Marchegiani G, Paiella S, Malleo G, Ciprani D, Gasparini C, et al. Impact of preoperative biliary drainage on postoperative outcome after pancreaticoduodenectomy: An analysis of 1500 consecutive cases. Dig Endosc. 2018;30:777-784

29. Ngu W, Jones M, Neal CP, Dennison AR, Metcalfe MS, Garcea G. Preoperative biliary drainage for distal biliary obstruction and post-operative infectious complications. ANZ J Surg. 2013;83:280-6.

30. Wang Q, Gurusamy KS, Lin H, Xie X, Wang C. Preoperative biliary drainage for obstructive jaundice. Cochrane Database Syst Rev. 2008;(3):CD005444.

31. Chou WC, Liu KH, Lu CH, Hung YS, Chen MF, Cheng YF, et al. To Operate or Not: Prediction of 3-Month Postoperative Mortality in Geriatric Cancer Patients. J Cancer. 2016;7:14-21.

32. Sia GB, Soares PFC, Gestic MA, Chaim EA, Callejas-Neto F, Cazzo E. Surgical management of cystic lesions of the pancreas: a single-centre experience. Arq Gastroenterol. 2018; 55:1-5.

33. Markossian TW, O’Neal CM, Senkowski C. Geographic disparities in pancreatic cancer survival in a southeastern safety-net academic medical center. Aust J Rural Health. 2016;24:73-8

34. van Roest MH, van der Aa MA, van der Geest LG, de Jong KP. The Impact of Socioeconomic Status, Surgical Resection and Type of Hospital on Survival in Patients with Pancreatic Cancer. A Population-Based Study in The Netherlands. PLoS One. 2016;11:e0166449.

35. Cazzo E, Ramos AC, Pareja JC, Chaim EA. Nationwide Macroeconomic Variables and the Growth Rate of Bariatric Surgeries in Brazil. Obes Surg. 2018. doi: 10.1007/s11695-018-3318-5.

36. International Surgical Outcomes Study group. Global patient outcomes after elective surgery: prospective cohort study in 27 low-, middle- and high-income countries. Br J Anaesth. 2016;117:601-9. 